\title{
Periampüller divertikül endoskopik retrograd kolanjiyopankreatografide kanülasyon başarısı ve komplikasyon sıklığını etkiler mi?
}

\author{
Do periampullary diverticula affect cannulation success and frequency of complications in endoscopic \\ retrograde cholangiopancreatography?
}

\author{
(D) Bilal TOKA ${ }^{1}$, DSalih TOKMAK²
}

Sağlık Bilimleri Üniversitesi Konya Eğitim ve Araştırma Hastanesi, 'Gastroenteroloji Kliniği, Konya

Bartın Devlet Hastanesi, ${ }^{2}$ Gastroenteroloji Kliniği, Bartın

Giriş ve Amaç: Periampüller divertiküller, endoskopik retrograd kolanjiyopankreatografi işlemi esnasında özellikle yaşlı hastalarda sık rastlanan anomalilerdir. Periampüller divertiküllerin endoskopik retrograd kolanjiyopankreatografide teknik başarı ve komplikasyonlar üzerine etkisi ile ilgili yapılan çalışmaların sonuçları ise çelişkilidir. Çalışmamızda periampüller divertikülü olan ve olmayan hastalar arasında endoskopik retrograd kolanjiyopankreatografi işlemi esnasında kanülasyon başarısı ve erken komplikasyonları karşılaştırmayı ve bunları etkileyen faktörleri değerlendirmeyi amaçladık. Gereç ve Yöntem: 2018-2020 yılları arasında endoskopik retrograd kolanjiyopankreatografi yapılan hastalar retrospektif olarak çalışmaya alındı. Hastalar periampüller divertikülü olmayan $(n=574)$ ve olan $(n=137)$ şeklinde iki gruba ayrıldı. Hastaların tıbbi kayıtları incelenerek her iki grup demografik ve klinik özellikleri, endoskopik retrograd kolanjiyopankreatografi işlem özellikleri, komplikasyon ve mortalite oranları açııından karşılaştırıldı. Bulgular: Ortalama

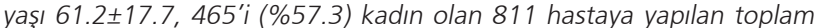
973 endoskopik retrograd kolanjiyopankreatografi işlemi incelendi. Kanülasyon başarısı periampüller divertikülü olmayan grupta \%97, periampüller divertikülü olan grupta \%97.1 ( $p=0.96$ ) saptandı. Endoskopik retrograd kolanjiyopankreatografide seans sayısı, işlem başarısı, koledok taşı varlığı, taş çıkarmak için büyük balon ile papilla dilatasyon ihtiyacı ve biliyer stent konulma oranları açısından gruplar benzerdi ( $p$ $>0.05$ ). Periampüller divertikül bulunmayan grupta kanülasyon için ön kesi ihtiyacı daha yüksekti (sırasıyla; \%25 vs \%14.6, p=0.01). Endoskopik retrograd kolanjiyopankreatografiye bağlı erken komplikasyonlar açısından ise gruplar arasında farklılık saptanmadı (periampüller divertikülü olmayanlarda $n=21, \% 3.1$, periampüller divertikülü olanlarda $n=5$, \%3.6, $p=0.75)$. Sonuç: Endoskopik retrograd kolanjiyopankreatografi esnasında periampüller divertikül saptanması kanülasyon önünde bir engel olarak görülmemeli, hatta ön kesi ihtiyacını azaltarak kanülasyonu kolaylaştırabileceği dikkate alınmalıdır. Çalışmamızın sonuçları periampüller divertiküllerin varlığının işleme bağlı komplikasyonlar açısından ek risk oluşturmadığını göstermektedir.

Anahtar kelimeler: Endoskopik retrograd kolanjiyopankreatografi, periampüller divertikül, duodenal divertikül

Illetişim: Bilal TOKA

Konya Eğitim ve Araştırma Hastanesi Endoskopi Ünitesi, Ayanbey Mah. Yeni Meram Cad. No:97 Meram / Konya

E-mail: bilaltoka@hotmail.com
Background and Aims: Periampullary diverticulas are frequent anomalies found during endoscopic retrograde cholangiopancreatography, especially in elderly patients. Previous study results on the effect of periampullary diverticula on technical success and complications in endoscopic retrograde cholangiopancreatography are controversial. In this study, we aimed to compare the cannulation success rate and early complications between patients with and without periampullary diverticula during endoscopic retrograde cholangiopancreatography, and to evaluate the factors affecting them. Material and Methods: Patients who underwent endoscopic retrograde cholangiopancreatography between 2018 and 2020 were retrospectively included in the study. The patients were divided into two groups: patients with periampullary diverticula $(n=137)$ and patients without periampullary diverticula $(n=574)$. Patients' medical records were analyzed, and the groups were compared in terms of dermographic and clinical features, cannulation success, need for precut sphincterotomy, balloon-papilla dilatation, biliary stent placement, the number of endoscopic procedures, complications, and mortality. Results: A total of 973 endoscopic retrograde cholangiopancreatography procedures were performed on 811 patients (465 [57.3\%] women). The mean patient age was 61.2 \pm 17.7 years. The cannulation success rate was $97 \%$ in the non-periampullary diverticula group and $97.1 \%(p=0.96)$ in the periampullary diverticula group. The groups were similar in terms of the number of endoscopic retrograde cholangiopancreatography sessions, the success rate of the procedure, the presence of choledocolitiazis, the need for balloon-papilla dilatation, and biliary stent placement rates $(p>0.05)$. The need for precut sphincterotomy was higher in the non-periampullary diverticula group (25\% vs. $14.6 \%$, respectively; $p=0.01)$. There was no difference between the groups in terms of early complications related to endoscopic retrograde cholangiopancreatography (21 [3.1\%] in the non-periampullary diverticula group, and $5[3.6 \%]$ in the periampullary diverticula group; $p=0.75)$. Conclusion: Periampullary diverticula detection during endoscopic retrograde cholangiopancreatography should not be considered an obstacle for cannulation success, and it can help facilitate the cannulation by reducing the need for precut sphincterotomy. The results of our study show that the presence of periampullary diverticula also does not increase the risk of procedure-related complications.

Key words: Endoscopic retrograde cholangiopancreatography, periampullary diverticulum, duodenal diverticulum
Toka B, Tokmak S. Do periampullary diverticula affect cannulation success and frequency of complications in endoscopic retrograde cholangiopancreatography? The Turkish Journal of Academic Gastroenterology 2020;19:83-89. DOI: 10.17941/agd.771435

Geliş Tarihi: 15.06.2020 • Kabul Tarihi: 30.06.2020 


\section{GíRiş}

Duodenal divertiküllerin bağırsak duvarını besleyen büyük damarların veya koledoğun giriş yerinde oluşan bir defekt ve bu bölgede gelişen herniasyon sonucu meydana geldiği düşünülmektedir (1). Papillaya bitişik ya da 2 ile $3 \mathrm{~cm}$ mesafede bulunan duodenal divertiküllere periampüller divertikül (PAD) adı verilir, papillayı içerisine alabilir veya papilla komşuluğunda bulunabilirler (2). PAD'ler genellikle asemptomatiktirler, ancak koledokolitiazis ve distal koledok darlığına yol açarak obstrüktif sarılık etiyolojisinde rol alabilirler $(3,4)$. Insidansı yaşla birlikte artar, 40 yaşın altında nadiren görülürken ileri yaşlarda prevalansı \%32'ye kadar çıkmaktadır (5).

Periampüller divertiküller, endoskopik retrograd kolanjiyopankreatografi (ERCP) işlemi esnasında papillanın görüntülenmesine veya uygun pozisyon sağlanmasına engel olarak koledoğun kanülasyonunu zorlaştırabilirler. ERCP esnasında PAD olan hastalarda PAD olmayan hastalara göre kanülasyon oranı ve komplikasyon riski konusunda literatürde az sayıda çalışma mevcut olup veriler çelişkilidir. Eski tarihli çalışmalar çoğunlukla PAD'lerin ERCP esnasında kanülasyon zorluğu oluşturduğunu ve komplikasyon riskini artırdığını gösterirken (6-8), son zamanlarda yapılan bazı çalışmalar ise ek kanülasyon tekniklerine daha çok intiyaç duyulmakla birlikte kanülasyon oranı ve komplikasyon sıklığının benzer olduğunu raporlamışıı (912). Ayrıca papillanın divertiküle göre yönünün de kanülasyon başarııını etkilediği gösterilmiştir (10).

Biz de klinik gözlemlerimiz ışı̆ıında, zaman içerisinde gelişen ERCP teknikleri ve işlem esnasında kullanılan cihazlardaki yeniliklerin etkisiyle duodenal divertikülü olan hastalarda ERCP işleminin daha yüksek başarı ile tamamlandığını düşünmekteyiz. Çalışmamızda çeşitli endikasyonlarla ERCP işlemine alınıp PAD tespit edilen hastalar ile PAD'ı bulunmayan hastaları kanülasyon başarısı, tedavi başarısı ve işleme bağlı komplikasyonlar açısından karşılaştırmayı amaçladık.

\section{GEREÇ ve YÖNTEM}

Çalışmamıza retrospektif olarak Ocak 2018-Mayıs 2020 tarihleri arasında Konya Eğitim ve Araştırma Hastanesi ve Bartın Devlet Hastanesi'nde ERCP yapılan hastalar alındı. Tüm işlemler anestezi eşliğinde ve sedasyon altında (propofol, midazolam, meperidin) her iki merkezde birer gastroenteroloji uzmanı (BT, ST) tarafından Fujinon $(4.2 \mathrm{~mm}$ çalışma kanalı; ED530, Japan) terapötik duodenoskop kullanılarak yapılmıştı. Hastalara işlem öncesi rektal veya intravenöz nonsteroid antiinflamatuvar verilmişti. Duodenal peristaltizm inhibisyonu için, gereken hastalarda, hyoscine N-butilbromide uygulanmıştı. Kanülasyon için öncelikle standart sfinkterotom (Ultratome; Boston Scientific, USA) ve içerisinden gönderilen kılavuz tel (Jagwire 0.035 inch; Boston Scientific) kullanıımıştı. Sfinkterotom ile 5 kez papillaya dokunularak yapılan deneme ve $5 \mathrm{dk}$ süreye rağmen koledok kanülasyonu sağlanamayan hastalarda iğne uçlu sfinkterotom ile ön kesi uygulanmıştı. 18 yaş altındakiler, gebeler, pankreatik kanala yönelik işlem yapılanlar, daha önce ERCP ile sfinkterotomi yapılmış olan hastalar, mide operasyonu geçirenler ve gerekli dosya bilgilerine ulaşılamayan hastalar çalışmadan çıkarıldı.

Kriterleri karşılayan hastaların çalışmaya katılan kliniklerde düzenli olarak tutulmakta olan tıbbi kayıtları ve hasta dosyaları incelenerek bilgileri kayıt altına alındı. Hastalar PAD tespit edilen ve edilmeyen olmak üzere iki gruba ayrıldı. Her iki grup demografik ve klinik özellikleri, kanülasyon başarısı, kanülasyon için ön kesi gerekliliği, büyük balon ile papilla dilatasyonu, tedavi için gereken endoskopik işlem sayısı, komplikasyon ve mortalite açısından karşılaştırıldı. Çalışma Konya Karatay Üniversitesi Tıp Fakültesi Etik Kurulunun 2020/032 sayılı kararı ile onaylanmıştır.

\section{İstatistiksel Analiz}

Çalışmamızda elde edilen verilerin istatistiksel analizi Windows için SPSS (Statistical Package for Social Sciences) 24.0 (SPSS Inc., Chicago, Illinois, USA) programı kullanılarak yapıldı. Oranların karşllaştıııması için "Ki-kare" ve "Fisher's Exact test", ortalamaların karşılaştırılması için ise "Student-t" ve "Mann Whitney-U" testleri kullanıldı. Sonuçlar medyan (minimum - maksimum) ve ortalama \pm SD olarak sunuldu ve P değerinin 0.05 ten küçük olması istatistiksel olarak anlamlı kabul edildi.

\section{BULGULAR}

Konya Eğitim ve Araştırma Hastanesi ve Bartın Devlet Hastanesi'nde Ocak 2018 ile Mayıs 2020 tarihleri arasında ERCP yapılan 902 hastadan kriterleri karşılayan 811'i çalışmaya alındı (Figür 1). Hastaların ortalama yaşı $61.2 \pm 17.7$ olup $465^{\prime} \mathrm{i}$ (\%57.3) kadındı. Toplam 137 (\%16.9) hastada PAD tespit edildi. Hastaların 787'sinde (\%97) koledok standart yöntemle kanülize edilebilmiş ve ERCP işlemi teknik olarak başarılyla tamamlanmıştı. Ortalama ERCP seans sayısı $1.20 \pm 0.55$ olup, en çok 4 seans (7 hastada) işlem uygulanmıştı. Hastalarda en sık koledok taşı $(n=568, \% 70)$ ve pankreas kanseri $(n=42, \% 5.2)$ tanıları saptandı. Çalışmaya alınan hastaların demografik özellikleri, laboratuvar bulguları ve ERCP işlem bulguları Tablo 1'de sunulmuştur. Periampuller divertikül tespit edilen grupta hastaların yaş ortalaması olmayanlara göre $(72 \pm 12.2$ vs $59 \pm 17.8, p<0.001)$ daha yüksek olup cinsi- 


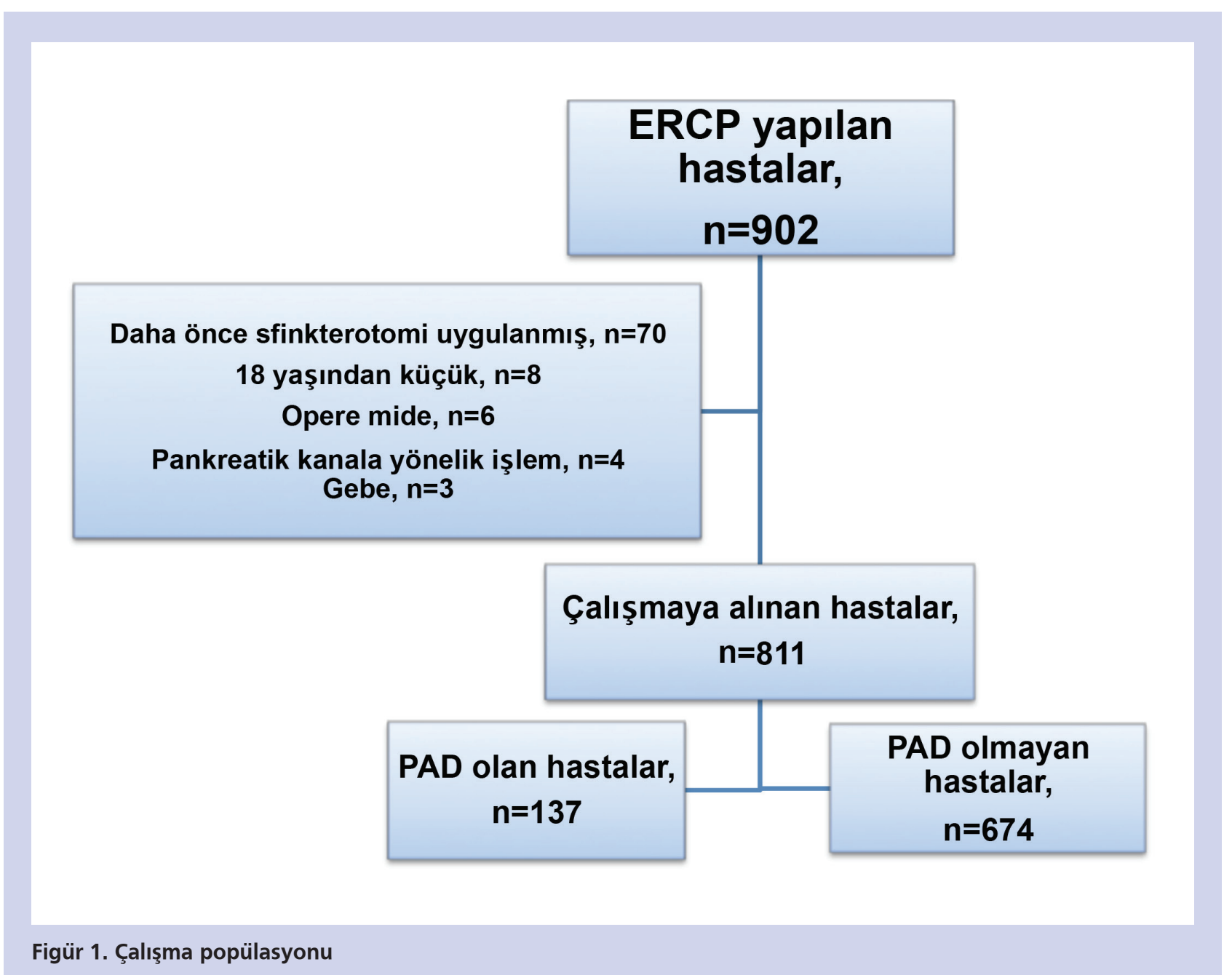

yet açısından her iki grup benzerdi ( $p=0.22)$. Kanülasyon başarısı her iki grupta benzerken (PAD olmayan: \%97, PAD olan: \%97.1, p=0.96), PAD olmayan grupta PAD grubuna göre koledok kanülasyonu için ön kesi ihtiyacı daha sık gelişmişti (sırasıyla; \%25 vs \%14.6, $p=0.01$ ). Gruplar işlem başarısı, koledok taşı ekstraksiyon oranları, taş çıkarmak için balon ile papilla dilatasyon ihtiyacı açısından benzerdi (Tablo 2).

PAD grubundaki 137 hastadan 72'sinde (\%42.4) divertikül papillaya göre saat 5, 44'ünde (\%32.1) saat 7 ve 21 'inde (\%15.3) saat 6 yönünde lokalize idi. ERCP esnasında kanülasyon sağlanamayan 4 hastanın divertikül lokalizasyonu papillaya göre; biri (\%1.4) saat 5, 2'si (\%4.5) saat 7 ve biri (\%4.8) saat 6 yönünde olup divertikülü olan hastalarda divertikül lokalizasyonu ile kanülasyon başarısızlığı arasında anlamlı ilişki saptanmadı ( $p=0.53)$.

ERCP işlemine bağlı erken komplikasyon sıklığı açısından gruplar benzerdi (PAD olmayan grupta $n=21, \% 3.1$, PAD olan grupta $n=5, \% 3.6, p=0.75)$. PAD olmayan grupta 10 hastada pankreatit ( 9 hafif, 1 orta şiddette), 6 hastada sfinkterotomiye bağlı hemoraji ve 2 hastada kolanjit görülürken, PAD grubunda 3 hastada pankreatit (tümü hafif şiddette) ve bir hastada hemoraji gelişti. Pankreatit, hemoraji ve kolanjit gelişim sıklığı açısından her iki grup benzer olup (sırasıyla $p=0.55,0.85$ ve 0.52 ) tümü aynı seansta endoskopik veya sonrasında medikal olarak tedavi edildi. Gruplar perforasyon sıklığı açısından benzer ( $p=0.66$ ) bulundu (Tablo 3). PAD olmayan grupta 3 hastada Stapfer tip 2 perforasyon gelişti, bu hastalardan 2 'si tam kaplı metal stent ile, bir hasta ise cerrahi olarak tedavi edildi. PAD olan grupta bir hastada Stapfer tip 3 perforasyon gelişti, 10 gün yatarak antibiyoterapi verilen hastada cerrahi tedavi gereksinimi oluşmadı. Çalışmaya alınan hastaların hiçbirinde ERCP işlemine bağlı erken dönemde mortalite saptanmadı. 
TOKA ve ark.

Tablo 1. Hastaların demografik özellikleri, laboratuvar bulguları ve ERCP sonuçları.

ERCP İşlemine Alınan Hastalar

$\mathbf{n}=\mathbf{8 1 1}$

\begin{tabular}{|c|c|c|}
\hline \multicolumn{2}{|l|}{ Yaş, mean, yll $\pm S D$} & $61.2 \pm 17.7$ \\
\hline \multicolumn{2}{|l|}{ Cinsiyet, kadın, n (\%) } & $465(57.3)$ \\
\hline \multicolumn{2}{|l|}{$A L T, I U / m l$, ortalama $\pm S D$} & $192 \pm 178$ \\
\hline \multicolumn{2}{|l|}{ AST, IU/ml, ortalama $\pm S D$} & $159 \pm 174$ \\
\hline \multicolumn{2}{|l|}{ GGT, IU/ml, ortalama \pm SD } & $447 \pm 383$ \\
\hline \multicolumn{2}{|l|}{ Total bilirübin, mg/dl, ortalama $\pm S D$} & $4.9 \pm 5.8$ \\
\hline \multicolumn{2}{|l|}{ Beyaz küre, x1000/ml } & $9.3 \pm 5.7$ \\
\hline \multirow[t]{4}{*}{ ASA skoru, n (\%) } & 1 & $615(53.1)$ \\
\hline & 2 & $184(22.7)$ \\
\hline & 3 & $164(20.2)$ \\
\hline & 4 & $34(3.9)$ \\
\hline \multirow[t]{3}{*}{ Papil lokalizasyonu, n (\%) } & Bulbus & $19(2.3)$ \\
\hline & Duodenum 2. kısım & $783(96.5)$ \\
\hline & Duodenum 3. kısım & $9(1.1)$ \\
\hline \multirow[t]{4}{*}{ Duodenal divertikül ve pozisyonu, $\mathrm{n}(\%)$} & Saat 5 & $72(52.6)$ \\
\hline & Saat 6 & $21(15.3)$ \\
\hline & Saat 7 & $44(32.1)$ \\
\hline & Toplam & $137(16.9)$ \\
\hline \multirow[t]{6}{*}{ Papil yapısı, n (\%) } & Normal & $743(91.6)$ \\
\hline & Tümöral & $12(1.5)$ \\
\hline & Fibrotik & $23(2.8)$ \\
\hline & Yarık şeklinde & $10(1.2)$ \\
\hline & Ayrı açılan kanal & $3(0.4)$ \\
\hline & Taş sıkışık & $20(2.5)$ \\
\hline \multicolumn{2}{|l|}{ Ön kesi gerekliliği, n (\%) } & $188(23.2)$ \\
\hline \multirow[t]{9}{*}{ Tanı, n (\%) } & Kanülasyon başarısız & $24(3)$ \\
\hline & Koledok taşı/Çamur & $568(70)$ \\
\hline & Pankreas Ca & $42(5.2)$ \\
\hline & Kolanjiyosellüler Ca & $33(4.1)$ \\
\hline & Benign biliyer darlık & $30(3.7)$ \\
\hline & SOD & $21(2.6)$ \\
\hline & Oddi tümörü & $17(2.1)$ \\
\hline & Postoperatif safra kaçağı & $16(2)$ \\
\hline & Diğer & $60(7.3)$ \\
\hline \multicolumn{2}{|l|}{ Ortalama seans sayısı, ortalama \pm SD } & $1.20 \pm 0.55$ \\
\hline \multicolumn{2}{|l|}{ Pankreatik kanala kılavuz tel, n (\%) } & $236(29.1)$ \\
\hline \multicolumn{2}{|l|}{ Balon ile papilla dilatasyonu, $\mathrm{n}(\%)$} & $93(11.5)$ \\
\hline \multicolumn{2}{|l|}{ Bilier stent, n (\%) } & $229(28.2)$ \\
\hline \multicolumn{2}{|l|}{ Pankreatik stent, n (\%) } & $38(4.7)$ \\
\hline \multicolumn{2}{|l|}{ ERCP'ye bağlı erken komplikasyon, n (\%) } & $26(3.2 \%)$ \\
\hline
\end{tabular}

ALT: Alanin aminotransferaz; AST: Aspartat aminotransferaz; GGT: Gama glutamil transferaz; ASA: American Society of Anesthesiologists; SOD: Sfinkter Oddi disfonksiyonu ERCP: Endoskopik retrograd kolanjiyopankreatografi, PAD: Periampüller divertikül. 
Tablo 2. PAD olan ve olmayan grupların karşılaştırılması.

\begin{tabular}{|c|c|c|c|}
\hline & $\begin{array}{c}\text { PAD Olmayan } \\
n=674\end{array}$ & $\begin{array}{l}\text { PAD Olan } \\
n=137\end{array}$ & p \\
\hline Yaş, yıl, ortalama \pm SD & $59 \pm 17.8$ & $72 \pm 12.2$ & $<0.001$ \\
\hline Cinsiyet, kadın, n (\%) & $380(66.2)$ & $85(62)$ & .22 \\
\hline Kronik hastalık, n (\%) & $297(44.1)$ & $83(60.6)$ & $<0.001$ \\
\hline $\mathrm{ALT}, \mathrm{IU} / \mathrm{ml}$, ortalama $\pm \mathrm{SD}$ & $198.6 \pm 172$ & $154.2 \pm 204.8$ & 0.04 \\
\hline AST, IU/ml, ortalama $\pm S D$ & $161.7 \pm 167.5$ & $145 \pm 203.4$ & .40 \\
\hline GGT, IU/ml, ortalama \pm SD & $460.7 \pm 394.9$ & $374.2 \pm 302$ & .02 \\
\hline T. bilirübin, $\mathrm{mg} / \mathrm{dl}$, ortalama $\pm \mathrm{SD}$ & $5.08 \pm 5.94$ & $3.99 \pm 4.80$ & .052 \\
\hline Lökosit sayısı, X1000/ml & $9,4 \pm 5.8$ & $9.1 \pm 4.5$ & .73 \\
\hline İşlem sayısı, ortalama \pm SD & $1.21 \pm 0.57$ & $1.17 \pm 0.46$ & .13 \\
\hline Kanülasyon başarısı, n (\%) & $654(97)$ & $133(97.1)$ & 0.96 \\
\hline Ön kesi ile sfinkterotomi, n (\%) & $168(25)$ & $20(14.6)$ & 0.01 \\
\hline Pankretik kanala kılavuz tel, n (\%) & $197(29.2)$ & $39(28.5)$ & .86 \\
\hline Balonla papilla dilatasyonu, n (\%) & $71(10.5)$ & $23(16.7)$ & .10 \\
\hline Koledok çapı, mm, ortalama \pm SD & $11.6 \pm 4.9$ & $13.7 \pm 5.7$ & $<0.001$ \\
\hline Taş varlığı, n (\%) & $426(74.3)$ & $104(76)$ & .45 \\
\hline Biliyer stent, n (\%) & $45(6.7)$ & $4(2.9)$ & .09 \\
\hline Erken komplikasyon, n (\%) & $21(3.1)$ & $5(3.6)$ & .75 \\
\hline
\end{tabular}

ALT: Alanin aminotransferaz; AST: Aspartat aminotransferaz; GGT: Gama glutamil transferaz; T. Bilirübin: Total bilirübün; ERCP: Endoskopik retrograd kolanjiyopankreatografi, PAD: Periampüller divertikül.

Tablo 3. Komplikasyonların karşılaştırılması.

\begin{tabular}{|lccc|} 
& PAD Olmayan, $\mathbf{n = 6 7 4}$ & PAD Olan, $\mathbf{n = 1 3 7}$ & p \\
\hline Pankreatit, $\mathrm{n}(\%)$ & $10(1.5 \%)$ & $3(2.2 \%)$ & 0.55 \\
\hline Hemoraji, $\mathrm{n}(\%)$ & $6(0.9 \%)$ & $1(0.7 \%)$ & 0.85 \\
\hline Kolanjit, $\mathrm{n}(\%)$ & $2(0.3 \%)$ & $0(0 \%)$ & 0.52 \\
\hline Perforasyon, $\mathrm{n}(\%)$ & $3(0.4 \%)$ & $1(0.7 \%)$ & 0.66
\end{tabular}

\section{TARTIŞMA}

Periampüller divertiküllerin ilerleyen yaşla birlikte sıklığı artmakta ve bu hastalarda koledokolitiazis başta olmak üzere pankreatobiliyer hastalıkların daha sık görüldüğü bilinmektedir (3). ERCP yapılan hastalarda ortalama $\% 10-20$ oranında PAD saptanmaktadır $(5,13,14)$. Bizim çalışmamızda da literatür ile uyumlu şekilde ERCP yapılan hastalarda PAD saptanma oranı \%16.9 olup $(5,13,18)$, PAD olan grubun yaş ortalaması daha yüksek (sırasılya; $72 \pm 12.2$ ve $59 \pm 17.8 \mathrm{yll}, \mathrm{p}<0.001$ ) idi. Her iki grup arasında koledok kanülasyon başarısı (\%97 vs \%97.1, $\mathrm{p}=0.96$ ) ve komplikasyon oranları (\%3.1 vs \%3.6, p=0.75) açısından fark tespit edilmemiş olup PAD olan hastalarda kanü- lasyon için ön kesiye intiyaç daha azdı (sırasıyla; \%25 vs $\% 14.6, p=0.01$ ). Periampüller divertikülü olan hastaların olmayanlar ile karşılaştırılığı çalışmalarda kanülasyon veya terapötik başarı oranları arasında birbiriyle çelişen sonuçlara rastlamak mümkündür $(6,14),(10,11),(15)$. Sonuçlar arasındaki bu değişkenlik yıllar içerisinde endoskopik teknik ve cihazlardaki gelişmeler, çalışmaların tasarımı ve hasta seçim kriterlerindeki farklııklar gibi faktörlere bağlı olabilir. Bu faktörler dışlandığında PAD olan hastaların çoğunluğunda kanülasyon sağlanamamasının en önemli nedeninin endoskopistin deneyim eksikliği ve buna bağlı olarak papillanın endoskopik olarak görüntü- 
lenememesi olduğu düşünülmektedir (13). Çalışmamızda incelenen tüm hastalarda papillanın endoskopik olarak görüntülenebilmiş olması, PAD'li hastalarda kanülasyon başarısının yüksek bulunmasını etkileyen önemli faktörlerdendir. Yakın zamanda yayınlanan bir metaanaliz ise; genellikle 2000 ylından önceki çalışmalarda PAD olan hastalarda kanülasyon ve tedavi başarısı daha düşükken, 2000 yılından sonra yapılan çalışmalarda benzer saptandığını göstermektedir (12). PAD hastalarında kanülasyon başarısındaki zaman içerisinde gözlenen bu artış yeni geliştirilen cihazların sağladığı teknik avantajlar ile birlikte gelişen manipülasyon teknikleri ve ERCP konusunda deneyim artışı ile ilişkili olarak değerlendirilebilir.

Periampuller divertiküllü hastalarda kanülasyon güçlüğü ile ilişkilendirilen faktörlerden biri de papillanın divertiküle göre pozisyonudur. Bu hastalarda papilla divertiküle göre en sık saat yönüne göre 5, 6 ve 7 pozisyonlarında izlenmekle birlikte nadiren farklı lokalizasyonlarda da yer alabilmektedir. Yapılan bir çalışmada diğer lokalizasyonlarla kanülasyon zorluğu arasında ilişki saptanmazken divertiküle göre saat 1 pozisyonunda olan papillalarda kanülasyonun daha zor sağlanabildiği gösterilmiştir (10). Bizim çalışmamızda değerlendirilen hastalarda PAD'lerin çoğu saat 7 yönünde (\%42.4) olup saat 1 yönünde PAD gözlenmemiş ve $P A D$ yönü ile kanülasyon başarısı arasında anlamlı ilişki saptanmamıştır $(p=0.53)$.

Yapılan çalışmalarda PAD olan hastalarda koledok kanülasyonunun, olmayan hasta gruplarına göre daha fazla efor gerektirdiği gösterilmiştir $(16,17)$. Ancak yapılan bir çalışmada kanülasyon için gereken girişim sayısının PAD tespit edilmeyen grupta daha fazla olduğu rapor edilmiş olup (18), güncel bir başka çalışmada da PAD olmayan grupta PAD olan hastalara göre kanülasyon için ön kesi ihtiyacının daha fazla (sırasıyla; \%41.8 ve \%28.7, $\mathrm{p}=0.001$ ) olduğu gösterilmiştir (10). Biz de bu çalışmaya benzer şekilde PAD olmayan grupta kanülasyon için ön kesi intiyacının daha fazla olduğunu gözlemledik. PAD'li hastalarda biliyer manometri ile yapılan çalışmalar Oddi sfinkterinin kas tonusu ve kasılmalarının bu grup hastalarda daha az olduğunu göstermiştir (6). Bu anlamda kanülasyon esnasında bu hastalarda sfinkterin katetere görece

\section{KAYNAKLAR}

1. Psathakis D, Utschakowski A, Müller G, et al. Clinical significance of duodenal diverticula. J Am Coll Surg 1994;178:257-60.

2. Wu SD, Su Y, Fan $Y$, et al. Relationship between intraduodenal peri-ampullary diverticulum and biliary disease in 178 patients undergoing ERCP. Hepatobiliary Pancreat Dis Int 2007;6:299-302.

3. Bruno M, Ribaldone DG, Fasulo $R$, et al. Is there a link between periampullary diverticula and biliopancreatic disease? An EUS approach to answer the question. Dig Liver Dis 2018;50:925-30. daha az direnç göstermesi koledok kanülasyonunu kolaylaştıran faktörlerden biri olabilir. Ayrıca PAD hastalarında genellikle koledok çapının daha geniş olması da kanülasyon için avantaj sağlayabilir.

ERCP'ye bağlı erken dönemde pankreatit, kolanjit, kanama ve perforasyon gibi erken komplikasyonların sıklığı \%10'lara kadar çıkabilmektedir (20). Bazı çalışmalar PAD'li hastalarda olmayanlara göre ERCP'ye bağlı perforasyon ve kanama sıklığının daha fazla olduğunu göstermektedir $(16,21)$. Ancak özellikle son yillarda yapılan çalışmalar olmak üzere çoğu çalışmada PAD olan ve olmayan hastalarda ERCP sonrası erken komplikasyon sıklı̆ı bizim çalışmamızda da olduğu gibi (sırasıyla; \%3.6 ve $\% 3.1, p=0,75)$ benzer bulunmuştur $(18,19,22)$. Komplikasyon gelişen hastalar endoskopik ve medikal olarak tedavi edilirken, PAD olmayan grupta 1 hastaya perforasyon nedeniyle cerrahi tedavi uygulanmış, mortalite ise gözlenmemişti.

Çalışmamızın bazı kısıtılıkları bulunmaktadır. Bunlardan biri çalışmamızın retrospektif oluşu ve bu nedenle işlem süresi, fluoroskopi süresi ve kanülasyon süresi gibi ERCP işleminin zorluk derecesini gösteren bazı faktörlerin değerlendirilememiş olmasıdır. Ayrıca divertikül içi ve kenarında olan papilla tanımı incelenen verilerde net olarak gösterilmediğinden dolayı bu grup hastaların değerlendirilmesi yapılamamıştır. Literatürdeki çalışmaların çoğu üçüncü basamak referans hastanelerde seçilmiş hastalara çok sayıda farkı endoskopistler tarafından uygulanan işlemlerin sonuçlarını içermektedir. Çalışmamızın en önemli avantajlarından biri ERCP işlemlerinin ikinci basamak iki hastanede daha az seçilmiş bir hasta popülasyonunda ve benzer deneyimde iki endoskopist tarafından uygulanmış olması ve dolayısıyla daha homojen bir popülasyonu içermesidir.

Sonuç olarak, periampüller divertikül varlığının ERCP işleminde kanülasyon veya teknik başarıyı olumsuz yönde etkilemediği söylenebilir. Ayrıca yine bu grup hastalarda perforasyon dahil olmak üzere komplikasyonların da benzer oranda görüldüğünü söylemek mümkündür.

\section{"Tüm yazarlar herhangi bir çıkar çatışması olmadığı- nı beyan ederler."}

4. Wijarnpreecha K, Panjawatanan P, Manatsathit W, et al. Association between juxtapapillary duodenal diverticula and risk of choledocholithiasis: a systematic review and meta-analysis. J Gastrointest Surg 2018; 22:2167-76

5. Chen L, Xia L, Lu Y, Bie L, Gong B. Influence of periampullary diverticulum on the occurrence of pancreaticobiliary diseases and outcomes of endoscopic retrograde cholangiopancreatography. Eur J Gastroenterol Hepatol 2017;29:105-11. 
6. Lobo D, Balfour T, Iftikhar S. Periampullary diverticula: consequences of failed ERCP. Ann R Coll Surg Engl 1998;80:326-31.

7. Leivonen MK, Halttunen JAA, Kivilaakso EO. Duodenal diverticulum at endoscopic retrograde cholangiopancreatography. Hepatogastroenterology 1996;43:961-6.

8. Chang-Chien CS. Do juxtapapillary diverticula of the duodenum interfere with cannulation at endoscopic retrograde cholangiopancreatography? A prospective study. Gastrointest Endosc 1987;33:298-300.

9. Jayaraj M, Mohan BP, Dhindsa BS, et al. Periampullary diverticula and ERCP outcomes: A systematic review and meta-analysis. Dig Dis Sci 2019;64:1364-76.

10. Parlak E, Suna N, Kuzu UB, et al. Diverticulum with papillae: does position of papilla affect technical success? Surg Laparosc Endosc Percutan Tech 2015;25:395-8.

11. Tham TC, Kelly M. Association of periampullary duodenal diverticula with bile duct stones and with technical success of endoscopic retrograde cholangiopancreatography. Endoscopy 2004;36:10503.

12. Mu P, Yue $P$, Li F, et al. Does periampullary diverticulum affect ERCP cannulation and post-procedure complications? an up-to-date meta-analysis. Turk J Gastroenterol 2020;31:193-204.

13. Corral JE, Mousa OY, Kröner PT, Gomez V, Lukens FJ. Impact of periampullary diverticulum on ERCP performance: A matched case-control study. Clin Endosc 2019;52:65-71.

14. Vaira D, Dowsett JF, Hatfield AR, et al. Is duodenal diverticulum a risk factor for sphincterotomy? Gut 1989;30:939-42.
15. Örmeci N, Deda X, Kalkan Ç, et al. Impact of periampullary diverticula on bile duct stones and ampullary carcinoma. Euroasian J Hepatogastroenterol 2016;6:31-4.

16. Zoepf T, Zoepf DS, Arnold JC, et al. The relationship between juxtapapillary duodenal diverticula and disorders of the biliopancreatic system: analysis of 350 patients. Gastrointest Endosc 2001;54:5661

17. Rajnakova A, Goh PM, Ngoi SS, et al. ERCP in patients with periampullary diverticulum. Hepatogastroenterology 2003;50:625-8.

18. Panteris V, Vezakis A, Filippou G, et al. Influence of juxtapapillary diverticula on the success or difficulty of cannulation and complication rate. Gastrointest Endosc 2008;68:903-10.

19. Tyagi P, Sharma P, Sharma BC, Puri AS. Periampullary diverticula and technical success of endoscopic retrograde cholangiopancreatography. Surg Endosc 2009; 23: 1342-5

20. Kapral C, Mühlberger A, Wewalka F, et al. Quality assessment of endoscopic retrograde cholangiopancreatography: results of a running nationwide Austrian benchmarking project after 5 years of implementation. Eur J Gastroenterol Hepatol 2012;24:1447-54.

21. Boender J, Nix GA, de Ridder MA, et al. Endoscopic papillotomy for common bile duct stones: factors influencing the complication rate. Endoscopy 1994;26:209-16.

22. Katsinelos P, Lazaraki G, Chatzimavroudis $G$, et al. Risk factors for therapeutic ERCP-related complications: an analysis of 2,715 cases performed by a single endoscopist. Ann Gastroenterol 2014;27:6572. 